\title{
O livro Carmelo Bene - Lectura Dantis como testemunho de um acontecimento
}

The book Carmelo Bene - Lectura Dantis

\author{
as a testimony of an event
}

\section{Silvia Balestreri}

Silvia Balestreri

Professora Associada do

Departamento de Arte Dramática e do Programa de Pós-Graduação em Artes Cênicas do Instituto de Artes da Universidade Federal do Rio Grande do Sul (UFRGS)

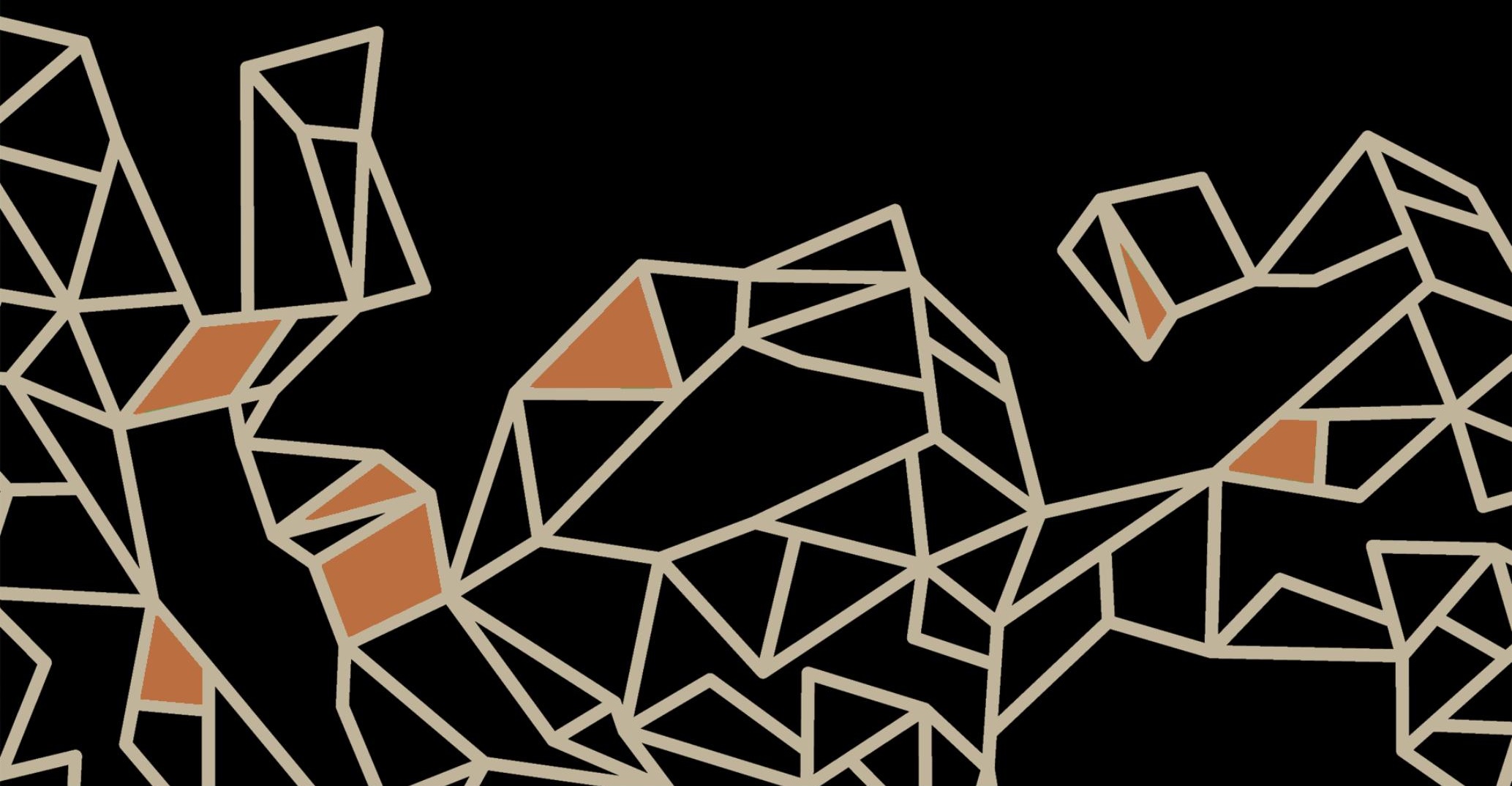




\section{Resumo}

Resenha de Carmelo Bene - Lectura Dantis: cronaca e testimonianze di un grande evento, organizado por Rino Maenza. O livro apresenta, com relatos, fragmentos de jornais da época e o encarte com um DVD, uma participação arrebatadora de Carmelo Bene (1937-2002) no primeiro aniversário daquele que foi o mais sangrento massacre acontecido na Itália nos chamados "anos de chumbo", em que grupos de extrema direita e de extrema esquerda se lançaram em ações de sequestro e atentados, assombrando a rotina das principais cidades da península.

Palavras-chave: Carmelo Bene, Lectura Dantis, Massacre, Bolonha.

\section{Abstract}

This text is about the book Carmelo Bene - Lectura Dantis: cronaca e testimonianze di un grande evento, organized by Rino Maenza. The book, sold with a DVD, shows a sweeping performance of Carmelo Bene (1937-2002) in the first anniversary of the bloodiest massacre that took place in the so-called Italian "years of lead".

Keywords: Carmelo Bene, Lectura Dantis, Massacre, Bologna.

Carmelo Bene (Campi Salentina, Puglia, 1937 - Roma, 2002), ator, diretor, romancista, poeta e cineasta, ao longo de seus mais de quarenta anos de intensa vida artística, colecionou polêmicas, admiradores e detratores, algumas críticas destruidoras - mais no início da carreira - e outras embevecidas com sua genialidade, além de ensaios que o alçam à condição de grande inovador do teatro italiano no século XX. Tão surpreendente quanto sua obra tem sido o destino de seu legado, devido a querelas entre as herdeiras, decididas judicialmente em sentido contrário ao que havia previsto Bene em seu testamento. Os documentos que deveriam ser amplamente divulgados e disponibilizados para pesquisadores e demais interessados, mediante a criação da Fundação Imemorial Carmelo Bene, segundo desejo do artista, estão, em vez disso, sob posse de duas pessoas não previstas no testamento para geri-los. Como consequência, o acesso aos arquivos pessoais do artista e as autorizações para traduções, reedição de livros, exposições e publicação de muitos materiais têm 
sido dificultados a ponto de alguns itens - tais como livros, discos e cartazes de espetáculos - terem se tornado peças raras de colecionador.

Se, por um lado, há essa dificuldade para a publicação de traduções e reedição de livros, por outro, percebe-se na Itália uma profusão de novas publicações relacionadas ao legado de Bene, seja de resultados de pesquisas recentes, seja por tornarem públicas informações, relatos, entrevistas e outros materiais produzidos em algum momento da vida do artista, mas somente agora preparados para publicação. Este é o caso do livro Carmelo Bene Lectura Dantis: cronaca e testimonianze di un grande evento, de Rino Maenza, que apresentaremos a seguir.

O livro, publicado em 2016 pela Edizione Grafiche Sigem, de Modena, Itália, sob a coordenação de Rino Maenza, contém 79 páginas ilustradas e o encarte de um DVD, produzido pelo mesmo Rino Maenza e por Angela Tomasini, responsável pelas filmagens em 31 de julho de 1981, quando ainda era uma jovem estudante de cinema. A publicação teve apoio da Região Emilia-Romagna, uma das unidades administrativas da República Italiana, que tem Bolonha como capital. Trata-se da reedição do livro Carmelo Bene legge Dante, também organizado por Maenza, publicado em 2007 por Marsilio Editore, de Veneza, e igualmente acompanhado de DVD do evento de que trata o livro.

Subdividido em sete partes, o livro apresenta uma espécie de prólogo e uma introdução, seguidos dos seguintes capítulos, aqui listados em livre tradução nossa: "Gênese do evento"; "A polêmica contra Carmelo Bene e o seu Dante"; "A encenação: o projeto"; "O evento". "Dante, Carmelo, Nossa Senhora e cem mil na sombra dos Asinelli: utopia da realidade"; "Assim tantos o viram: comentários, críticas e opiniões na imprensa". O DVD, uma preciosidade que emocionou muitos italianos, é resultado de imagens e sonorização restauradas e digitalizadas e inclui também fotografias e cobertura da tragédia.

Bolonha é uma cidade do norte da Itália que preserva, em suas edificações, marcos históricos da Idade Média. Uma das características do centro histórico são suas torres, erguidas, especula-se, como demonstração de poder e para segurança e defesa das famílias então proprietárias. Atualmente restaram duas dezenas de torres na cidade, mas supõe-se que já foram aproximadamente uma centena.

Dentre essas duas dezenas que chegaram aos nossos dias, mantêm-se, como símbolos da cidade, duas torres muito próximas entre si, uma com 
quase o dobro de altura da outra: as torres Garisenda (47 m) e degli Asinelli (97,20 m). Conhecidas como Due Torri - "duas torres" - situam-se estrategicamente na entrada da cidade histórica e são monumentos de referência da vida civil da cidade e mesmo um símbolo desta.

Em 2 de agosto de 1980, início do período de veraneio na Europa, às 10h25 da manhã, uma bomba explode na sala de espera da segunda classe na Estação Central de Trens da cidade de Bolonha. O local serve de ligação para vários destinos, por isso havia muita gente. Contaram-se 85 mortos e duzentos feridos. Alguns integrantes de grupos neofascistas foram presos, mas a autoria do atentado nunca ficou bem esclarecida. Bolonha, a vermelha, assim é conhecida essa cidade, pela cor de seus telhados e pela forte presença de partidos de esquerda. Esse atentado, que é considerado o maior e mais sangrento na Itália do pós-guerra, foi atribuído ao grupo neofascista Núcleo Armado Revolucionário (NAR), entretanto, mais de 38 anos depois, ainda não foi satisfatoriamente solucionado. Em 2018, foi feita a coleta de novos e reveladores depoimentos e a exumação do cadáver de uma vítima, para obtenção de dados adicionais para investigação.

Para o primeiro aniversário do massacre na Estação Central de Bolonha, o então prefeito da cidade, Renato Zangheri, reconhecido professor de história econômica e ativista cultural, pensou em um grande ato civil que se estendesse por quatro dias, ao qual compareceriam jovens de toda a Europa. Rino Maenza, produtor e responsável pela sonorização da leitura de Bene, conta que, alguns meses antes, em uma caminhada pela cidade após uma apresentação do espetáculo Majakovskij, do próprio Bene, este e o prefeito conversaram sobre a realização desse evento de quatro dias, em um dos quais Carmelo Bene faria uma leitura pública de versos da Divina Comédia, de Dante Alighieri. Segundo Maenza, Bene, inicialmente reticente à recitação de Dante em praça pública, acabou por aceitar o convite e decidiram que seria feito nas Duas Torres, tendo sido por fim realizado, mais especificamente, do primeiro andar da Torre degli Asinelli, a mais alta torre inclinada medieval existente atualmente na Itália.

A pretensão de Zangheri era que houvesse, durante os quatro dias, diferentes manifestações artísticas e de homenagem aos mortos. O recital de poesia caberia a Carmelo Bene. Segundo Maenza (2016, p. 10), a participação 
de Bene acabou por se tornar "o evento", devido à mobilização e à comoção que suscitou. Foi o prefeito quem escolheu os cantos da Divina Comédia que deveriam ser apresentados. Dentre estes, os cantos XVIII e XXIII do "Inferno", nos quais Dante menciona, respectivamente, fraudulentos, alcoviteiros e sedutores e, no outro, se refere aos hipócritas, falando de Bolonha e dos bolonheses. Para um jornal, Bene declara: "Eu, de início, fiquei um pouco surpreso que o prefeito de Bolonha tenha escolhido estes dois cantos sobre os bolonheses, mas depois a coisa me pareceu divertida" (MAENZA, 2016, p. 10, tradução nossa).

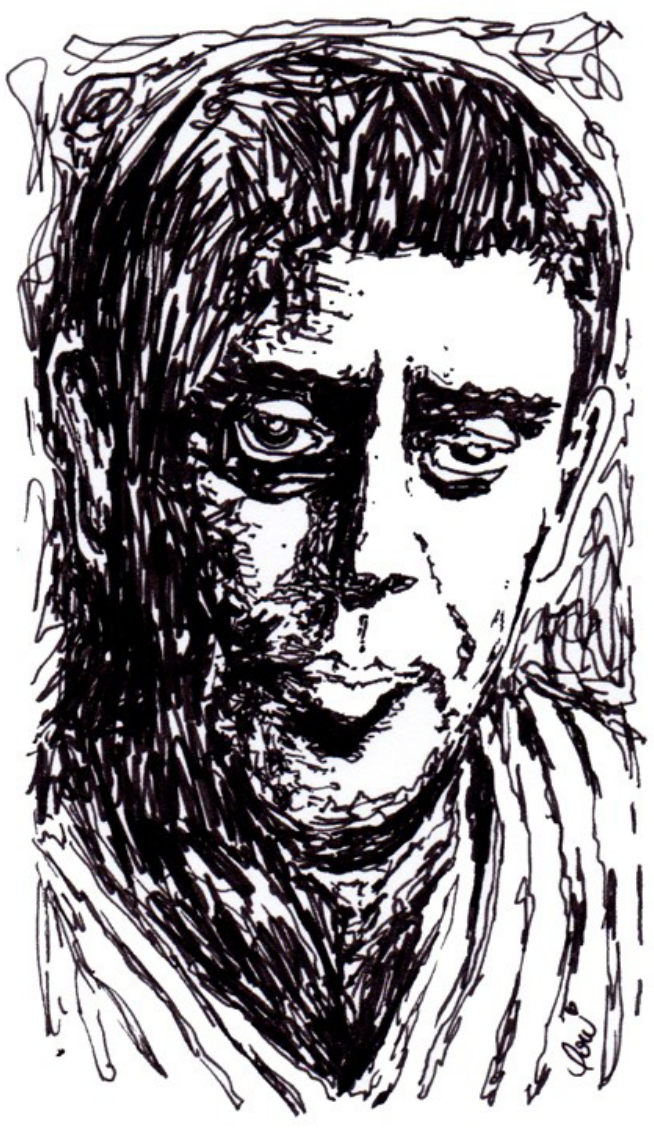

Figura 1 - Desenho a partir de foto de Bene na coletiva de imprensa da Lectura Dantis ${ }^{1}$

Ao final, foram escolhidos versos dos cantos V, XXVI e XXXIII do "Inferno", dos cantos VI e VIII do "Purgatório" e dos cantos XXIII, XXVII e VII - nessa ordem - do "Paraíso". Ao final, em meio a aplausos, quase como um bis, Bene recita dois sonetos, também de Dante Alighieri - "Guido, I' Vorrei" e "Tanto

1 Desenho de Dom (Domenico Ban Junior) a partir de foto de autor não identificado (MAENZA, 2016, p. 12). Retrato de linha contínua, sem esboço, com caneta fineline $0.05 \mathrm{~mm}$. 
Gentile". Nos versos e nas ênfases que Ihes dá Carmelo Bene, evocações de uma Itália ultrajada, de um corpo morto, de um povo sobre quem o mar volta a se fechar, mas também de união, alegria, amor e um suspiro para a alma, para citar algumas evocações, que ganham contornos singulares nas variações da voz de Bene.

De fato, nos dias programados, a cidade de Bolonha recebeu muitos jovens, que se acomodaram em acampamentos e albergues, contradizendo alguns políticos de oposição que apostaram no fracasso da empreitada. Renato Zangheri, de sua parte, comemorou o sucesso desse ato de luta contra o terrorismo, que, por sua vez, se satisfaz com o silêncio e o medo, e que "teve uma resposta muito forte, de massa, unitária" (MAENZA, 2016, p. 18), ou, como escreve o próprio Rino Maenza (2016, p. 18), além de um sucesso da luta contra o terrorismo, foi um sucesso "dos valores que se queriam afirmar: a vida, a cultura, a liberdade".

A participação de Carmelo Bene no evento foi arrebatadora. Mas, nos momentos que a precederam, essa participação foi alvo de críticas e pivô de polêmicas e disputas envolvendo políticos de esquerda, de direita e também setores da Igreja. Ao ser perguntado sobre o evento, Bene deu uma declaração ao periódico /l Resto del Carlino, que desagradou a muitos católicos: disse que seria uma "festa sagrada, no sentido pagão, como o banquete que em algumas tradições se faz após o luto. Não na maneira cato-laica, isto é, “idiota”'. E prosseguiu: “(veja o Dizionario dei Sinonimi, de Tommaseo, onde o termo equivale a "repugnante")" (MAENZA, 2016, p. 15, tradução nossa).

Se Carmelo Bene não fazia parte de movimentos nem de partidos de esquerda, muito menos o fazia à direita. Na Igreja Católica, certamente não tinha uma boa aceitação, apesar de sua longa experiência infantil como coroinha, a qual ele atribui sua primeira e longa vivência como espectador de um evento cênico, nas milhares de missas a que deu assistência em sua cidade natal, Campi Salentina. Seus primeiros espetáculos eram cheios de heresias e seu filme mais conhecido e premiado, Nossa Senhora dos Turcos, retorce um acontecimento em que mártires teriam alcançado a santidade, atribuindo uma Nossa Senhora a seus algozes.

Uma afirmação da cerimônia do aniversário do massacre em Bolonha como um evento pagão e não repugnante (não "cato-laico"), além dos versos 
de Dante que mencionavam os bolonheses de um modo nada simpático, criou um tremendo mal-estar e críticas de políticos da Democracia Cristã - partido de direita - à participação de Bene no evento. Alguns diretores da Radiotelevisione Italiana (RAI), que estava comprometida a fazer uma transmissão ao vivo do evento para a Europa, o que aumentaria em muito seu alcance, eram democratas cristãos, o que talvez explique a mudança de rumos e o fato de não ter havido uma filmagem completa da apresentação de Bene na torre. Durante muitos anos, apenas o registro sonoro e algumas poucas imagens eram conhecidas. Antes, porém, a RAI lhe pediu o roteiro da apresentação, ao que Bene retrucou: "Mas como? Não têm um exemplar da Divina Comédia?" Tendo sido cancelada a transmissão televisiva, Bene garantiu sua combinação com o prefeito Zangheri e confirmou sua apresentação na torre para o recital poético.

A apresentação de Carmelo Bene começou no horário combinado, às 22 h15 de 31 de julho de 1981, segundo dia do grande evento em Bolonha. Era verão, e o sol se põe muito tardiamente na Europa. O primeiro refletor se acendeu às $21 \mathrm{~h} 30$, iluminando o público. A aparelhagem sonora instalada para a apresentação era como a de um show da banda Pink Floyd à época - fator que aumentou bastante os custos dessa participação beneana, o que também foi motivo para controvérsias. Bene fazia pouco que havia iniciado suas experiências de recitais concertísticos, com ênfase ainda maior no aspecto sonoro dos espetáculos. Subiu ágil as escadas para a primeira sacada da Torre degli Asinelli, a torre medieval mais alta de todas as atualmente existentes, de onde recitou os versos de Dante. Nas ruas e praças do entorno, vários jornais mencionaram haver por volta de 100 mil pessoas ou mais. Cem mil pessoas em silêncio, que explodiram em aplausos ao final e pediram bis, concedido por Bene, lendo dois sonetos de Dante também significativos para o momento.

Matérias de jornais da época, primorosamente agrupadas por Maenza ao final do livro, fazem respingar em nós sensações vividas naquele momento: cerca de 100 mil pessoas escutaram em silêncio - mais de um veículo informa essa grande quantidade de público - e houve uma calorosa ovação ao final. Através dessa leitura, ficamos sabendo que as luzes do entorno foram apagadas e somente a torre e o ator foram iluminados, que Bene fascinou 
milhares de Bolonheses e que tal sucesso calou seus detratores, que Bene é uma voz sem corpo através de mixers e amplificadores, sendo provavelmente o primeiro ator italiano da era tecnológica, que propiciou a muitos um retorno a Dante, libertos da relação oficial determinada durante suas vidas escolares. Um detrator ainda diz que o propósito foi narcisista e o custo para a cidade foi muito alto. Mas, em geral, vê-se muito entusiasmo nas matérias que se seguiram à noite dantesca de e com Carmelo Bene (MAENZA, 2016, p. 61-69).

Não havendo registro fílmico da apresentação inteira, devido ao boicote e à censura da RAI na ocasião, mais de 25 anos após aquela noite, a videomaker Angela Tomasini, então uma cineasta amadora, encontrou em um baú fitas VHS nas quais havia registrado, de um ângulo muito favorável, a leitura de Bene naquele evento. Assim, vieram a público as imagens da apresentação completa, cujo DVD acompanha o livro de Maenza. A publicação desse volume fez reviver em alguns espectadores - ou testemunhas - a intensidade daquele momento. Bene, já falecido quando foram encontradas essas imagens, é mencionado como um fantasma que retorna, um espírito trágico que se manifesta. $\mathrm{E}$, em um segundo momento, aos 30 anos desse acontecimento, alguns que o testemunharam voltam a se emocionar, ou a se (co) moverem, como diria Bene (MAENZA, 2016, p. 69-79).

A leitura dos versos da Divina Comédia por Bene, como qualquer leitura sua, não foi uma interpretação do texto, mas um compor-se com ele, explorando suas virtualidades, fazendo aparecer nuances, tessituras e sentidos ainda não revelados. Essa relação com o texto permite descobrir ritmos e sentidos até então velados. As tomadas audiovisuais daquele momento ou mesmo pequenas partes dessa Lectura Dantis divulgadas na plataforma digital YouTube ${ }^{2}$, em contraste com a leitura dos mesmos trechos por outros atores italianos famosos, mostram a diferença entre interpretar - como em Roberto Benigni e Vittorio Gassman - e compor-se com o texto, extraindo daí sonoridades e sentidos inusitados. Ao final, Bene pede desculpas pela interferência do vento e dedica aquela noite aos feridos do horrendo massacre, não aos mortos, mas aos feridos. Carmelo Bene, em ocasião posterior, ao se referir a esse momento, atestou: Sono apparso alla Madonna! - Eu apareci

2 Por exemplo Carmelo... (2007). 
para Nossa Senhora! Bene assumiu, em seu primeiro livro autobiográfico, que a Nossa Senhora para a qual apareceu era a multidão presente à sua leitura de Dante (BENE, 2010), mas há controvérsias a respeito.

\section{Referências bibliográficas}

BENE, C. Sono apparso alla Madonna. Dante a Bologna 31-07-1981. In: BENE, C.

Sono apparso alla Madonna. 3. ed. Milano: Bompiani, 2010. p. 75-86.

CARMELO Bene chiama Benigni: lectura dantis. 8'35". medianova. YouTube. 2007 Disponível em: https://www.youtube.com/watch?v=y7Exlch69ro\&t=269s. Acesso em: 18 mar. 2019. MAENZA, R. (org.). Carmelo Bene legge Dante. Veneza: Marsilio, 2007. (DVD com livro). MAENZA, R. (org.). Carmelo Bene - Lectura Dantis: cronaca e testimonianze di un grande evento. Modena: Sigem, 2016. (Livro e DVD).

Recebido em 02/07/2019

Aprovado em 10/07/2019

Publicado em 30/08/2019 